\title{
QUALITY OF LIFE SCALE IN PARKINSON'S DISEASE
}

\section{PDQ-39 - (Brazilian Portuguese version) to assess patients with and without levodopa motor fluctuation}

\author{
Renata Guzzo Souza', Vanderci Borges', \\ Sonia Maria Cesar de Azevedo Silva², Henrique Ballalai Ferraz ${ }^{2}$
}

\begin{abstract}
Quality of life (QoL) is an important treatment outcome indicator in Parkinson's disease (PD). The aim of this study is to assess the usefulness of the Parkinson's disease questionnaire - PDQ-39 (Brazilian Portuguese Version) in measuring QoL of PD patients with or without motor fluctuations. Fifty-six PD patients with mean disease duration of 7.4 years were assessed and 41 of them (73.3\%) had motor fluctuations. The PDQ-39 has eight dimensions ranging from 0 to 100; being the higher the score, the worse the QoL. Comparing groups with and without motor fluctuations showed that the dimensions mobility, activities of daily living ( $A D L)$, communication and bodily discomfort scored higher in the fluctuating group. There was a tendency to see that the higher the Hoehn and Yahr (HY) scale stages, the higher the PDQ39 scores. Patients suffering from the disease for more than five years had worse PDQ-39 scores only in the items ADL and communication, when compared with those with the disease for $\leq 5$ years. The PDQ-39 is an instrument that detects decrease in QoL of PD patients and the presence of motor fluctuations predicts QoL reduction.
\end{abstract}

KEY WORDS: Parkinson's disease, quality of life, psychomotor performance, levodopa

\begin{abstract}
Escala para qualidade de vida na doença de Parkinson - PDQ 39 (versão do Português falado no Brasil) como instrumento para avaliação de pacientes com e sem flutuação motora decorrente da levodopa

RESUMO - A qualidade de vida (QdV) é um item importante para se mensurar o sucesso do tratamento na doença de Parkinson (DP). O objetivo deste estudo foi o de avaliar a utilidade do questionário sobre a doença de Parkinson - PDQ-39 (versão em língua portuguesa falada no Brasil) para mensurar a QdV dos pacientes parkinsonianos com e sem flutuação motora. Nós avaliamos 56 pacientes com DP com tempo médio da doença de 7,4 anos, e destes 41 (73,3\%) apresentavam flutuação motora. A PDQ-39 tem oito domínios que variam de 0 a 100 e quanto maior o escore pior a QdV. A comparação dos grupos de pacientes com e sem flutuação motora mostrou que os domínios: mobilidade, atividades de vida diária, comunicação e desconforto corporal tinham escores maiores nos flutuadores. Quanto maiores os estágios de Hoehn e Yahr (HY) da doença, maiores os escores da PDQ-39. Pacientes com mais de 5 anos de evolução da doença mostraram escores piores da PDQ39 apenas nos itens atividades da vida diária e comunicação se comparados a pacientes com 5 anos ou menos de doença. A PDQ-39 é um instrumento capaz de detectar declínio da QdV de pacientes com DP e a presença de flutuação motora é um preditor para redução na QdV.
\end{abstract}

PALAVRAS-CHAVE: doença de Parkinson, qualidade de vida, desempenho psicomotor, levodopa.

Parkinson's disease (PD) ranks second in prevalence of degenerative disease of the nervous system, after Alzheimer's disease, and it is estimated that $0.3 \%$ of population is affected 1 . A recent Brazilian study carried out in the town of Bambuí, State of Minas Gerais, Brazil, showed that PD affects 3.3\% of individuals aged over 65 years ${ }^{2}$.
Especially in its initial stages, PD symptoms are mainly motor, later on cognitive dysfunctions and mood disorders appear. Although levodopa still is the cornerstone of PD treatment, its prolonged use is associated to motor and non-motor complications. Non-motor complications include nausea, vomiting, orthostatic hypotension, sleepiness, hallucinations

\footnotetext{
Movement Disorders Unit, Department of Neurology, Universidade Federal de São Paulo, São Paulo SP, Brazil (UNIFESP): ${ }^{1}$ Nurse; ${ }^{2} \mathrm{MD}$, Neurologist.

Received 16 January 2007, received in final form 13 April 2007. Accepted 31 May 2007.

Dra. Renata Guzzo Souza - Rua Estado de Israel 493 / 72 - 04022-001 São Paulo SP - Brasil. E-mail: renatags18@hotmail.com renataguzzosouza@ig.com.br
} 
and delusions. The main motor complications are effect fluctuations and dyskinesias. Fluctuations may either be predictable, as the wearing-off of medication, or unpredictable, as random oscillations (on-off effect) or delayed "on" effect. Dyskenesias are characterized by involuntary movements, sometimes stereotyped. They may emerge either during the motor benefit period ("on" period dyskenesia) or during the absence of this motor effect ("off" period dyskenesia). Although daily activities may be affected since the beginning, progression of symptoms and complications cause a progressive decrease in the QoL. In this context, QoL refers to the impact of the disease on patients themselves, including physical, emotional, and socio-economic aspects ${ }^{3}$.

There are several instruments to measure health and health-related quality of life that require checking reliability, accessibility, and receptivity, as well as interpretation, in order to be validated. There are several PD-specific instruments to assess motor functions, such as the Unified Parkinson's Disease Rating Scale (UPDRS), the Schwab-England Scale, and others ${ }^{4,5}$. However, these scales do not take into account the actual impact of the disease on patients' daily life, because they do not have a satisfactory approach of cognitive and emotional symptoms. There are several instruments to assess quality of life in PD: PIMS (Parkinson's Disease Impact Scale), PLQ (Parkinson Lebensqualität - Parkinson's Disease Quality of Life Questionnaire), PDQL (Parkinson's Disease Quality of Life Questionnaire), PDQ-39 (Parkinson's Disease Questionnaire), and SF-36 (Health Status Questionnaire, short form), among others ${ }^{6-10}$. The 39-item Parkinson's disease questionnaire (PDQ-39) is one of the most often used instruments to measure treatment effect on QoL. It assesses several clinical features and has been tested and used in several studies and is available in several languages. It was developed interviewing PD patients about harmful effects of the disease regarding several aspects of their daily life. At first, 65 items were used in a pilot test. Redundant items were eliminated, thus originating a smaller questionnaire with 39 questions divided into 8 dimensions and measuring the impact of PD on the QoL in the previous month ${ }^{9}$. Recentely, a Brasilian version of it was valited ${ }^{11}$.

The aim of this study is to assess the usefulness of a Brasilian version of PDQ-39 in PD patients with and without motor fluctuation.

\section{METHOD}

Patients - Using the UK Parkinson's Disease Society's Brain Bank ${ }^{12}$ criteria, we evaluated 56 patients with the di- agnosis of Parkinson's disease undergoing outpatient treatment at the Movement Disorders Unit of the Department of Clinical Neurology of the Universidade Federal de São Paulo (UNIFESP).

Men and woman patients aged over 40 years, in any phase of the disease, who accepted to participate in the study and signed the informed consent form were included. Patients with severe cognitive impairment, evaluated by neurologists using Mini-Mental State Examination (MMSE), who were not able to answer the questionnaire were excluded.

Procedure - First, a non-healthcare professional translated the original English version of the PDQ-39 into Brazilian Portuguese. The back-translation was done by another translator to check possible mistakes or cultural biases. The questionnaire was then reviewed by its authors to make it easily accessible and compatible with the patient's reality.

The PDQ-39 comprises 39 questions with five different options of answer related to the frequency of the disease manifestation. The answers refer to impact of the illness on the patient's life in the previous month, as explained before the interview. The 39 questions are divided into 8 dimensions: mobility (10 questions), activities of daily living $(A D L)(6)$, emotional well-being (6), stigma (4), social support (3), cognition (4), communication (3), and bodily discomfort (3).

The score for each question ranges from zero (0) to four (4): "never"=0; "occasionally"=1; "sometimes"=2; "often"= 3; "always"=4. The final score is the result of the following equation: the sum of each question score divided by the result times 4 (the maximal score for each question), divided by the total number of questions. This result is multiplied times by 100. Each dimension score ranges from 0 to 100 in a linear scale, in which zero is the best and 100 the worst quality of life ${ }^{13}$.

After the patient's consent, the questionnaire, clinical and epidemiologic assessment forms were applied during routine outpatient visits. Patients were encouraged to answer the questionnaire by themselves. One of the authors (RGS) interviewed those who could not answer alone due to several reasons, such as decreased visual acuity, significant tremor, and akinesia.

The Hoehn and Yahr (HY) scale, ranging between stages 1 to 5, was used to assess disease severity and allow future comparison of results ${ }^{14}$. Data was collect from August 2005 until November 2006.

The patients were divided into two groups: those with fluctuations and/or dyskenesias and those without these changes. The criteria used to divide them into these groups were defined based on the interview and confirmed by the attending neurologist.

Statistical analysis - The Spearman correlation test was used to verify the relation between disease duration, $\mathrm{HY}$ stage, and presence of fluctuations, as well as to check if the dimensions were statistically significant. The Mann-Whitney test was used to detect possible differences in each dimension of PDQ-39 in groups of patients with presence or ab- 
sence of fluctuations and in groups with five or less years of disease duration and more than five years of duration.

\section{RESULTS}

Fifty-six PD patients were seen at the outpatient clinics of the Movement Disorders Unit, at the Universidade Federal de São Paulo (UNIFESP): 32 (57.2\%) were male and $24(42.8 \%)$, female. The mean age was 62.7 years, age range of 40 to 81 years; and the mean PD duration was 7.4 years. Forty-one $(73.3 \%)$ patients had motor fluctuations and $15(26.7 \%)$ stabilized with the use of medication.

The patient distribution in the HY scale was: in stage 1 , five patients $(8.9 \%)$; stage 1.5 , four patients $(7.1 \%)$; stage 2 , nine patients $(16 \%)$; stage 2.5 , twenty patients $(35.7 \%)$; stage 3 , eighteen patients (32.1\%). No stage-4 and 5 patients were assessed.

Out of 56 patients, 49 (87.5\%) were on levodopa. Patients without fluctuations used a mean levodopa dose of $216 \mathrm{mg} /$ day (ranging from $250 \mathrm{mg}$ to $500 \mathrm{mg} /$ day) while patients with motor complication took a mean dose of $537 \mathrm{mg}$ (ranging from $250 \mathrm{mg}$ to 2500 $\mathrm{mg}$ ). Seventeen patients (29.8\%) used anti-depressive medication.

The 56 patients had the following mean scores and respective standard deviations in the eight dimensions: mobility 50.9 \pm 26.1 ; ADL 44.4 \pm 28.5 ; emotional well-being $48.1 \pm 25.5$; stigma $33.5 \pm 31.8$; social support $67.7 \pm 12.7$; cognition $32.5 \pm 19.8$; communication $30.8 \pm 28.2$ and bodily discomfort $43.5 \pm 25.9$.
Cronbach's alpha coefficient of the 39 questions included in the PDQ-39 was 0.923 , demonstrating internal consistency and high reliability $(p<0.001)$.

Table 1 depicts the mean scores of the eight PDQ-39 dimensions in each HY stage. As expected, the Spearman test showed a correlation between HY stages and the degree of severity of the PDQ-39 dimensions, except for the items cognitions and social support.

As seen in Figure, the eight dimensions assessed showed the following mean scores: in the dimension mobility, it is 30.5 for patients without fluctuations and 58.3 for those with fluctuations; in ADL, 25.7 for patients without fluctuations and 51.3 with fluctuations; emotional well-being, 38.6 in those without fluctuations and 51.6 with fluctuations; in stigma, 22.9 in patients without fluctuations and 37.3 with fluctuations; in social support, 69.4 for patients without fluctuations and 67.1 with fluctuations; in cognition, 26.7 for patients without fluctuations and 34.6 with fluctuations; in communication, 10.0 for patients without fluctuations and 38.4 with fluctuations; in bodily discomfort, 32.2 in patients without fluctuations and $\mathbf{4 7 . 6}$ with fluctuations. According to the Mann-Whitney test, the differences were statistically significant $(p<0.05)$ for the items mobility, ADL, emotional well-being, communication, and bodily discomfort.

Table 2 depicts that disease duration only correlates with disease severity in the following PDQ-39 dimensions: ADL and communication.

Table 1. Mean scores of PDQ39 dimensions at Hohen and Yahr stages $(n=56)$.

\begin{tabular}{|c|c|c|c|c|c|c|}
\hline & $\begin{array}{c}\text { Stage } 1 \\
\text { Mean score } \\
\text { (SD) }\end{array}$ & $\begin{array}{l}\text { Stage } 1.5 \\
\text { Mean score } \\
\text { (SD) }\end{array}$ & $\begin{array}{c}\text { Stage } 2 \\
\text { Mean score } \\
\text { (SD) }\end{array}$ & $\begin{array}{c}\text { Stage } 2.5 \\
\text { Mean score } \\
\text { (SD) }\end{array}$ & $\begin{array}{c}\text { Stage } 3 \\
\text { Mean score } \\
\text { (SD) }\end{array}$ & $\begin{array}{c}\text { Correlation } \\
\text { coefficient } \\
\text { (p) }\end{array}$ \\
\hline Mobility & $\begin{array}{c}29.0 \\
(15.3)\end{array}$ & $\begin{array}{l}24.0 \\
(8.3)\end{array}$ & $\begin{array}{c}43.0 \\
(25.3)\end{array}$ & $\begin{array}{c}44.0 \\
(26.1)\end{array}$ & $\begin{array}{c}72.0 \\
(17.2)\end{array}$ & $\begin{array}{c}0.60 \\
(p<0.001)\end{array}$ \\
\hline Activities of daily living & $\begin{array}{l}13.0 \\
(7.2)\end{array}$ & $\begin{array}{c}9.0 \\
(8.6)\end{array}$ & $\begin{array}{c}52.0 \\
(22.4)\end{array}$ & $\begin{array}{c}39.0 \\
(27.1)\end{array}$ & $\begin{array}{c}61.0 \\
(26.6)\end{array}$ & $\begin{array}{c}0.50 \\
(p<0.001)\end{array}$ \\
\hline Emotions & $\begin{array}{c}43.0 \\
(29.8)\end{array}$ & $\begin{array}{c}32.0 \\
(11.0)\end{array}$ & $\begin{array}{c}46.0 \\
(24.3)\end{array}$ & $\begin{array}{c}42.0 \\
(25.8)\end{array}$ & $\begin{array}{c}58.0 \\
(26.6)\end{array}$ & $\begin{array}{c}0.26 \\
(p<0.05)\end{array}$ \\
\hline Stigma & $\begin{array}{c}10.0 \\
(16.3)\end{array}$ & $\begin{array}{c}11.0 \\
(21.9)\end{array}$ & $\begin{array}{c}40.0 \\
(38.0)\end{array}$ & $\begin{array}{c}30.0 \\
(31.0)\end{array}$ & $\begin{array}{c}44.0 \\
(30.2)\end{array}$ & $\begin{array}{c}0.31 \\
(p<0.05)\end{array}$ \\
\hline Social support & $\begin{array}{c}70.0 \\
(13.9)\end{array}$ & $\begin{array}{l}69.0 \\
(4.2)\end{array}$ & $\begin{array}{l}67.0 \\
(8.3)\end{array}$ & $\begin{array}{c}62.0 \\
(20.2)\end{array}$ & $\begin{array}{c}71.0 \\
(13.8)\end{array}$ & $\begin{array}{l}0.09 \\
\text { (NS) }\end{array}$ \\
\hline Cognitions & $\begin{array}{c}18.0 \\
(24.4)\end{array}$ & $\begin{array}{c}28.0 \\
(24.2)\end{array}$ & $\begin{array}{c}35.0 \\
(18.5)\end{array}$ & $\begin{array}{c}32.0 \\
(21.8)\end{array}$ & $\begin{array}{c}35.0 \\
(16.9)\end{array}$ & $\begin{array}{l}0.19 \\
\text { (NS) }\end{array}$ \\
\hline Communication & $\begin{array}{c}3.0 \\
(7.5)\end{array}$ & $\begin{array}{c}6.0 \\
(12.5)\end{array}$ & $\begin{array}{c}32.0 \\
(35.0)\end{array}$ & $\begin{array}{c}35.0 \\
(26.7)\end{array}$ & $\begin{array}{c}37.0 \\
(27.4)\end{array}$ & $\begin{array}{c}0.36 \\
(p<0.01)\end{array}$ \\
\hline Bodily discomfort & $\begin{array}{c}27.0 \\
(10.9)\end{array}$ & $\begin{array}{c}23.0 \\
(18.5)\end{array}$ & $\begin{array}{c}38.0 \\
(20.5)\end{array}$ & $\begin{array}{c}42.0 \\
(31.2)\end{array}$ & $\begin{array}{c}55.0 \\
(20.9)\end{array}$ & $\begin{array}{c}0.41 \\
(p<0.01)\end{array}$ \\
\hline
\end{tabular}

Statistical test, Spearman correlation analysis; NS, not significant. 


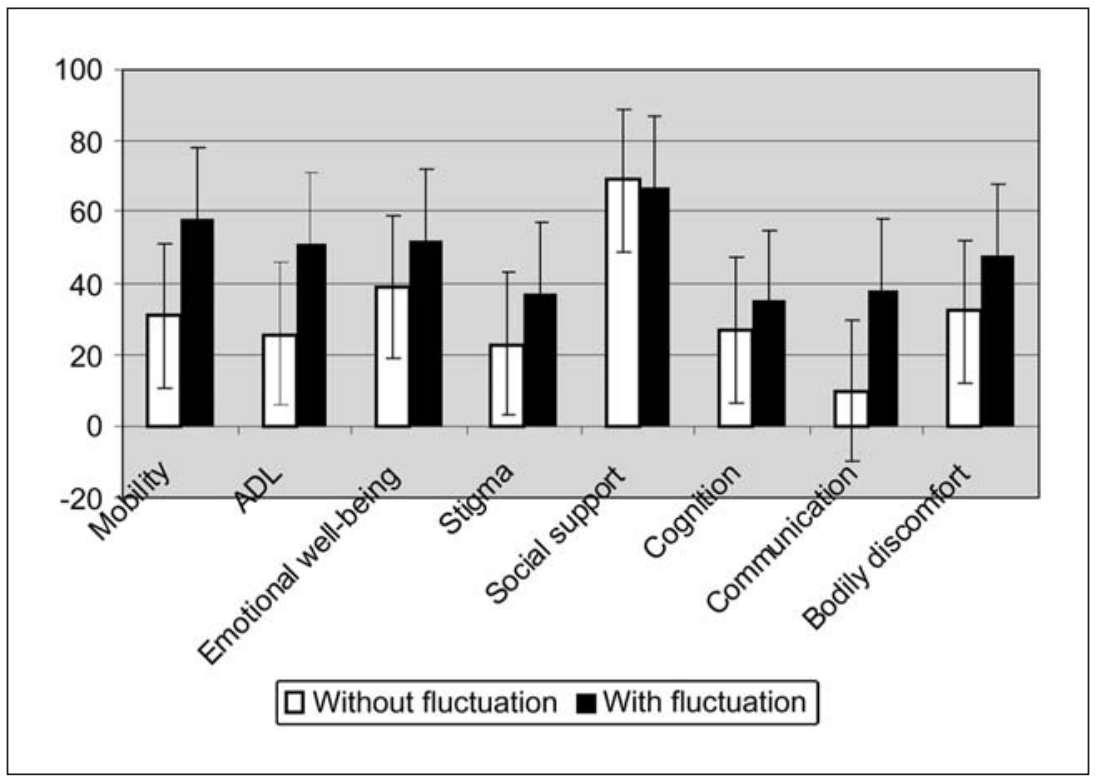

Figure. Mean scores of PDQ-39 dimensions in patients with and without motor fluctuation. Mann-Whitney test showed statistically significant differences $(p<0.05)$ for mobility, activities of daily living ( $A D L)$, emotions, communication, and bodily discomfort.
Table 2. Disease duration vs. mean scores of dimensions

\begin{tabular}{|c|c|c|}
\hline & $\begin{array}{c}\leq 5 \text { years } \\
(\mathrm{N}=25) \\
\text { Mean scores } \\
\text { (SD) }\end{array}$ & $\begin{array}{c}>5 \text { years } \\
(\mathrm{N}=31) \\
\text { Mean scores } \\
\text { (SD) }\end{array}$ \\
\hline Mobility & $47.5(28.5)$ & $53.6(24.0)$ \\
\hline Activities of daily living & $32.8(28.2)$ & $53.8(26.0)$ \\
\hline Emotional well-being & $50.5(26.3)$ & $46.2(24.9)$ \\
\hline Stigma & $25.2(27.6)$ & $40.1(33.5)$ \\
\hline Social support & $68.0(13.1)$ & $67.5(13.0)$ \\
\hline Cognition & $30.7(20.3)$ & $33.9(19.6)$ \\
\hline Communication & $21.3(27.4)$ & $38.4(26.8)$ \\
\hline Bodily discomfort & $40.7(23.6)$ & $45.7(26.9)$ \\
\hline
\end{tabular}

Mann-Whitney test demonstrated significant differences $(p<0.05)$ for activities of daily living and communication.

\section{DISCUSSION}

It is well known that PD is a chronic disease that significantly affects quality of life ${ }^{15}$. The PDQ-39 is frequently used to measure the impact of the disease on QoL, because it is the questionnaire most used worldwide and it includes the a number of items assessing PD impact. Other instruments, such as the Short Form 36 Health Survey (SF 36), Nottingham Health Profile, Sickness Impact Profile (SIP), among others, are good but general scales, not PD-specific ${ }^{16}$.

In the sample of 56 patients, $41(73.3 \%)$ had motor fluctuations. These changes are related to disease progression and prolonged use of levodopa, and play an important role in reducing QoL, because they affect mainly mobility and daily life activities, and are associated with muscle pain and depressive symptoms ${ }^{17,18}$.
The absence of HY stage- 4 and 5 patients in this sample is explained by the high cognitive impairment, usually seen on these stages which made them unable to answer the questionnaire, thus being excluded from the study.

This study showed that disease severity, when assessed by Hohen and Yahr stages, harmfully affects QoL in activities involving motor skills ${ }^{19}$, as seen in Table 1. The higher the disease stage, the worse the quality of life in aspects concerning physical independence ${ }^{20,21}$.

Studying the dimensions of emotional and cognitive aspects, it was observed that the results were not as expected. That is, the lower the disease stage, the higher the impact on QoL. This may be explained by the patients' initial reaction acknowledging they have an incurable, progressive disease and may become physically, emotionally and economically dependent, thus causing emotional problems. It is known that PD-associated depression sometimes precedes motor disabilities ${ }^{19,22}$.

Regarding the dimensions social support and stigma related to HY stages, previous studies have already shown that they are almost constant during the disease progression ${ }^{23}$, probably due to increased dissemination of information about PD by support groups or volunteer organizations clarifying it to the general population.

The presence of motor fluctuations causes a faster decline in QoL when compared to those without fluctuation ${ }^{17}$, as depicted in Figure, where the dimensions requiring greater bodily and motor inde- 
pendence have higher scores in patients with fluctuations, showing that motor deficits is an important factor in worsening QoL. Another factor that negatively affects QoL in PD is disease duration, as depicted in Table 2. However, this only happened in the items activities of daily life and communication. It is known that the longer the disease lasts, the worse the performance in all motor or cognitive activities, but in this sample we could not demonstrate statistically significant differences in most of dimensions.

In conclusion, our data demonstrate that the PDQ39 is a multidimensional instrument approaching physical, emotional, and environmental factors that are useful in the medical practice. It is easily understood and handled by patients, thus allowing a better assessment of the disease progression and drug therapy. Therefore, it is an important tool in making therapeutic decisions to minimize the effects of PD and improve the quality of life of PD patients.

\section{REFERENCES}

1. Lau LM, Breteler MM. Epidemiology of Parkinson's disease. Lancet Neurology 2006;5:525-535.

2. Barbosa MT, Caramelli P, Maia DP, et al. Parkinsonism and Parkinson's disease in the elderly: a community-based survey in Brazil (the Bambui study). Mov Disord 2006;21:800-808.

3. Martin PM. An introduction to the concept of quality of life in Parkinson disease. J Neurol 1998;245(Suppl 1):S2-S6.

4. Fahn S, Elton R. The unified Parkinson's disease rating scale. In Fahn S, Marsden C, Calne D, Golstein M (Eds). Recent developments in Parkinson's disease, Vol 2. New York: MacMillan 1987:153-304.

5. Schwab RS, England AC. Projection technique for evaluating surgery in Parkinson's disease. In Gillingham FJ, Donaldson IML (Eds). Third Symposium on Parkinson's disease. Edinburg: Livingstone 1969:152-157.

6. Calne S, Schulzer M, Mark M, et al. Validating a quality of life rating scale for idiopathic parkinsonism: Parkinson's impact scale. Parkinson Relat Disord 1996;2:55-61.
7. van den Berg M, Leben mit Parkinson: Entwicklung und psychometrische Testung des Fragenbogens PLQ. Neurol Rehabil 1998;4:221-226.

8. de Boer AG, Wijker W, Speelman JD, et al. Quality of life in patients with Parkinson's disease: development of a questionnaire. J Neurol Neurosurg Psychiatry 1996;61:70-74.

9. Peto V, Jenkinson C, Fitzpatrick R, et al. The development and validation of a short measure of functioning and well being for individuals with Parkinson's disease. Qual Life Res 1995;4:241-248.

10. Ware JE, Sherbourne CD. The MOS 36-item short form health status Survey (SF-36): I Conceptual framework and item selection. Med Care 1992;30:473-483.

11. Carod-Artal FJ, Martinez-Martin P, Vargas AP. Independent validation of SCOPA-psychosocial and metric properties of the PDQ-39 Brazilian version. Mov Disord 2007;22:91-98.

12. Hughes AJ, Daniel SE, Kilford L, Lees AJ. Accuracy of clinical diagnosis of idiophatic Parkinson's disease: a clinico-pathological study of 100 cases. J Neurol Neurosurg Psychiatry 1992;55:181-184.

13. Erola T, Karinen P, Heikkinen E, et al. Bilateral subthalamic nucleus stimulation improves health-related quality of life in Parkinsonian patients. Parkinson Relat Disord 2005;11:89-94.

14. Hoehn MM, Yahr MD. Parkinsonism onset, progression and mortality. Neurology 1967;17:427-442.

15. Damiano AM, Snyder C, Stausser B, Willin MK. A review of healthrelated quality-of-life concepts and measures for Parkinson's disease. Qual Life Res 1999;8:235-243.

16. Jenkinson C, Fitzpatrick R. Cross-cultural evaluation of the short form 8item Parkinson's disease questionnaire (PDQ-8): results from America, Canada, Japan, Italy and Spain. Parkinson Relat Disord 2007;13:22-28.

17. Garret MC, Rosas MJ, Simões F, Vieira S, Costa M. Does timing and dosage of levodopa modify drug-induced dyskinesias and motor fluctuations? A retrospective analysis. Parkinson Relat Disord 1994;4:99-102.

18. Stocchi F. Prevention and treatment of motor fluctuations. Parkinson Relat Disord 2003;9:73-81.

19. Slawek J, Derejko M, Lass P. Factors affecting the quality of life of patients with idiopathic Parkinson's disease-a cross-sectional study in an outpatient clinic attendees. Parkinson Relat Disord 2005;11:465-468.

20. Schrag A, Jahanshahi M, Quinn N. What contributes to quality of life in patients with Parkinson's disease? J Neurol Neurosurg Psychiatry 2000;69:308-312.

21. Reuther M, Spottke EA, Klotscher J, et al. Assessing health-related quality of life in patients with Parkinson's disease in a prospective longitudinal study. Parkinson Relat Disord 2007;13:108-114.

22. de Lau LML, Koudstaal PJ, Hofman A, Breteler MMB. Subjective complaints precede Parkinson disease. The Rotterdam Study. Arch Neurol 2006;63:362-365.

23. Martin PM, Dueñas MS, Baquero VV. Psychometric characteristics of the Parkinson's disease questionnaire (PDQ-39) - Ecuadorian version. Parkinson Relat Disord 2005;11:207-304. 